\title{
Cuba, ¿un obstáculo a la participación latinoamericana en el Movimiento de Países No Alineados? (1961-1984)
}

Cuba, and obstacle to Latin American participation in the Non-Aligned Movement? (1961-1984)

\author{
Germán Alburquerque Fuschini \\ Investigador asociado del Centro de Estudios Históricos \\ Universidad Bernardo O'Higgins, Chile \\ german.alburquerque@gmail.com \\ Diego Hernández \\ Investigador asociado Universidad Bernardo O'Higgins, Chile \\ diego.cipol@gmail.com
}

\begin{abstract}
Resumen
Este trabajo se pregunta si Cuba estimuló o dificultó la participación de las naciones latinoamericanas en el Movimiento de Países No Alineados. A partir de una investigación documental realizada en el archivo de la cancillería cubana, se revela la influencia activa ejercida por Cuba en el marco del No Alineamiento, que tuvo por objeto controlar la presencia del grupo latinoamericano en el seno del organismo. De esa manera se evidencia el concepto de No Alineación particular que formuló Cuba, y se discute la primacía de criterios pragmáticos o ideológicos en el manejo de su política exterior.
\end{abstract}

Palabras clave: Cuba; Movimiento de Países No Alineados; Revolución Cubana; Política exterior; América Latina, Tercer Mundo.

\begin{abstract}
This article addresses the question of whether Cuba was a bane or boon to the participation of Latin American nations in the Non-Aligned Movement (NAM). Based on archival research in the Cuban chancellery, this article demonstrates the passive influence and active steps taken by Cuba under the framework of the Non-Alignment, in order to control the presence of the Latin American group within the body of the organization. In this way, we demonstrate the concept of the Non-Alignment that was articulated by Cuba, and discuss the primacy of pragmatic or ideological criteria in the management of its foreign policy.
\end{abstract}

Keywords: Cuba; Non-Aligned Movement; Cuban Revolution; Foreign policy; Latin America; Third World.

Germán Alburquerque y Diego Hernández.

Cuba, ¿un obstáculo a la participación latinoamericana en el Movimiento de Países No Alineados? (1961-1984). Autoctonía. Revista de Ciencias Sociales e Historia, Vol. III, Nº1, Enero-Junio 2019, 54-67 ISSN 0719-8213

DOI: http://dx.doi.org/10.23854/autoc.v3i1.111 


\section{Introducción}

El objetivo de este artículo es determinar el papel jugado por Cuba en la incorporación de Estados latinoamericanos al Movimiento de Países No Alineados (MPNA) durante la Guerra Fría. A primera vista podría pensarse que Cuba fue la punta de lanza del continente en el Movimiento, debido, sobre todo, a que fue el primer miembro oficial latinoamericano en la organización y el único durante una década. Esa habría sido, además, la intención de Tito, el líder yugoslavo, al invitar a la Cuba revolucionaria a la fundacional conferencia del No Alineamiento de Belgrado el año 1961.

Para los cubanos el Movimiento, durante los años sesenta, no despertó gran interés. No constituía una preocupación central de su política exterior. Lo entendían como un espacio apropiado para manifestar su repudio al bloqueo estadounidense y para advertir al mundo de los planes de Washington contra la Revolución. Más energía dedicaron, en cambio, a la política de tricontinentalidad, que a mediados de década convocó a lo que ya se conocía como Tercer Mundo: los pueblos africanos, asiáticos y latinoamericanos subyugados históricamente por el imperialismo. Fue ésta una oportunidad para estrechar lazos con gobiernos, partidos políticos y grupos emancipadores de la periferia, erigiéndose La Habana como punto neurálgico del conglomerado. En 1966 se celebró allí la Conferencia Tricontinental, de donde emergió la Organización de Solidaridad de los Pueblos de África, Asia y América Latina, OSPAAAL. Se requeriría otra investigación para descubrir por qué el ímpetu y el espíritu de la tricontinentalidad decayeron; lo cierto es que en los años setenta los cubanos volcaron su atención hacia otra instancia similar, el MPNA, desplazando a la anterior.
En efecto, la política exterior cubana cambió en sintonía con una modificación del panorama político internacional. Hacia fines de los sesenta e inicios de los setenta la Unión Soviética estrechó su hegemonía sobre La Habana, a la vez que modificó su política hacia el Tercer Mundo en respuesta a la competencia china, que amagaba con quitarle la tutela del revolucionarismo global (Friedman, 2015; Allison, 1988). Ambos hechos se cruzaron en la idea de la alianza natural entre el orbe soviético y el bloque no alineado, como los cubanos explícitamente declaraban (Alburquerque, próxima aparición; Alburquerque, 2017a). Así, el No Alineamiento se convirtió en un objetivo axial de la política exterior de La Habana, que desde ese instante inició su escalada hasta lograr el liderazgo del organismo y encarrilarlo hacia dicha alianza. Se requería alcanzar cierta hegemonía en el Movimiento para imprimir ese cambio de rumbo, y en ese plan cada voto adquirió relevancia. Lo importante no era el espacio geográfico del que procedía el voto, sino su contenido favorable a las propias posiciones. Es por eso que los cubanos aprobaban el ingreso de un país solo si el gobierno que lo representaba era afín a su postura; de lo contrario era preferible que no entrara a la asamblea. A través de ese prisma Cuba evaluaría las posibilidades de cada país latinoamericano que manifestaba su intención de ingresar al MPNA.

Ello se enmarcaba, además, en la tensa relación existente entre La Habana y los países del continente, definida por la lógica de la Guerra Fría y por el enfrentamiento cubano con Estados Unidos. Como desde Washington se presionaba a los países latinoamericanos para que se distanciaran de Cuba y la excluyeran del foro continental -como ocurrió en la Organización de Estados Americanos, OEA-, los cubanos se relacionaban bajo ese condicionamiento con los 
países de la región; a ello se agregaba la voluntad cubana de apoyar las luchas revolucionarias que allí se libraran.

En los setenta, sin embargo, esto varió por cuanto la hegemonía soviética sobre Cuba se desplegó en función de la distensión del conflicto bipolar. Moscú conminó a los cubanos a mejorar las relaciones con los países de la región así como con los partidos comunistas tradicionales de cada nación, bajo el predicamento de que no se debía arriesgar el clima de armonía entre las potencias con aventuras revolucionarias que alteraran la zona de influencia estadounidense (Harmer, 2013; Domínguez, 1989). Veremos si esto se reflejó en lo concerniente al No Alineamiento. Abordar el modo en que Cuba influyó sobre la participación latinoamericana en el Movimiento implica adentrarse en lo que esta organización representó para el continente. La verdad es que los países latinoamericanos no prestaron mayor atención al MPNA hasta el umbral de la década del setenta. Para las primeras conferencias solo enviaron observadores, con la excepción de Cuba. Se le concebía como una agrupación, en esencia, afroasiática que poco coincidía con una América Latina que, por una parte, conocía -en su mayoría- de la independencia hacía más de un siglo, y que, por otra, se había resignado ya a pertenecer al área hegemonizada por EE.UU. Se ha señalado que cuando el Movimiento se orientó hacia reivindicaciones económicas y promovió el Nuevo Orden Económico Internacional, las naciones latinoamericanas se sintieron mejor representadas y empezaron a participar con mayor vigor (Ramírez, 2000; Dallanegra Pedraza, 1984). Aunque puede que ese factor incidiera, es manifiesto que los países que se adhirieron en los setenta lo hicieron de la mano de gobiernos con una sensibilidad de izquierda (en amplio sentido: reformistas, populistas, revolucionarios, nacionalistas), y que por ende, intervino un fuerte componente ideológico en la oleada que sumó a Chile, Perú, Argentina, Panamá y Nicaragua (también se sumó Bolivia; Ecuador y Colombia lo hicieron en los ochenta, bajo políticas distintas). En paralelo, en la zona del Caribe se experimentó -al igual que en África y Asia- un proceso de descolonización que supuso un incremento en el contingente regional en el Movimiento. Guyana, Surinam y Granada, entre otros, poseían un signo político similar al recién indicado.

¿Cuba constituyó un incentivo o un freno a la participación latinoamericana en el Movimiento? La respuesta debe asociarse al grado de idealismo o pragmatismo con que los cubanos se conducían, o sea, si profesaban un No Alineamiento universal, concibiendo el Movimiento como una organización fundamental que era necesario fortalecer con la incorporación de nuevos miembros; o bien si priorizaban el cálculo estratégico de cada voto, de acuerdo a su interés por encaminar al Movimiento por determinada senda. Los estudios especializados han concluido que la Cuba revolucionaria desarrolló una política exterior que combinaba equilibradamente elementos pragmáticos e ideológicos (Jorge Domínguez, 1989; Rusell Riechers, 2012), dando origen a una conducta internacional flexible y multifacética (Benemelis, 1990). ¿Qué habrá sucedido en el MPNA?

\section{Cuba y América Latina en el Movimiento de Países No Alineados}

La isla fue consciente de que revestía un significado especial ser el único representante del continente en el MPNA, de partida porque podía constituirse en un faro para el resto de los Estados: "La presencia de Cuba deberá contribuir a que los países latinoamericanos se sientan estimulados a seguir por el camino que abre las perspectivas de una mayor independencia."(Reunión consultiva, La Habana, 
1969). Рero además se imponía la misión de insertar la problemática realidad latinoamericana en el seno del organismo. Así, desde la primera Conferencia de Belgrado y a lo largo de toda su trayectoria, Cuba se esforzó por denunciar en el Movimiento los resabios del dominio colonial en el continente, en especial los que se ligaban directamente al imperialismo y a su más genuino representante, Estados Unidos. Partían por las propias reivindicaciones, vale decir, por el fin del bloqueo estadounidense y la devolución de la base de Guantánamo, para seguir por las de los vecinos: la entrega del Canal de Panamá; la independencia de Puerto Rico; el cese de las violaciones a los derechos humanos en Chile; la recuperación de las Islas Malvinas por parte de Argentina; y la supresión de la intervención estadounidense en Nicaragua, entre otras.

Pero una cosa era asumir la vocería de las naciones hermanas y otra muy distinta incrementar el número de miembros continentales del Movimiento, sobre todo porque esto incidía en la correlación de fuerzas al interior del colectivo. Cada caso fue distinto, y la influencia cubana también. Esta puede dividirse, a su vez, en pasiva y activa.

\section{Influencia pasiva}

La influencia pasiva no depende de la acción efectiva de Cuba, sino de las posiciones que adoptaba, las cuales generaban reacciones en terceros países: la sola presencia de Cuba en el MPNA podía condicionar la actitud -negativa o positiva- con que otros países latinoamericanos encaraban el Movimiento.

Negativa porque Cuba imprimía al Movimiento un sello de radicalismo y de antagonismo hacia Estados Unidos que podía ser riesgoso. Ad portas de la Conferencia No Alineada de 1964 en El
Cairo, un informe dirigido a la cancillería cubana aludía a ello: "El Embajador de Chile le manifestó al Embajador de la RAU aquí que la razón por la cual probablemente no participe su país en la reunión es por la posible participación de Cuba" (Carta confidencial del embajador de Cuba en Belgrado al presidente Osvaldo Dorticós, c.1964). Рага Chile era un factor disuasivo la participación cubana en Egipto por cuanto le dejaba en una situación comprometida ante Estados Unidos, que por esos años ejercía presión, por ejemplo, a través de la OEA y de la Alianza para el Progreso. Podemos suponer que lo de Chile se replicaba en otros países del continente sometidos a similares presiones.

No obstante, la influencia pasiva fue mucho más trascendente en su expresión positiva, es decir, en cuanto acicate a la participación latinoamericana. La adhesión que la Revolución Cubana captó en el continente incluyó a partidos, agrupaciones, sindicatos, federaciones estudiantiles, e incluso a militares. Cuando a partir de fines de los años sesenta algunos de estos actores llegaron al poder, el signo político de los gobiernos cambió y su política exterior giró de rumbo siguiendo en buena medida la estela de La Habana. Los militares peruanos que llegaron al poder en 1968 no ocultaron su simpatía por Cuba y, aún más, jugaron a su favor en la OEA. La inclusión de Perú en el Movimiento de Países No Alineados un par de años después, era coherente con el proyecto que Juan Velasco Alvarado y su equipo elaboraron y que tendía a desprenderse de la tutela estadounidense, рего también obedecía a lo que representaba el Movimiento, en tanto fuera una instancia al servicio de las reivindicaciones continentales, algo por lo cual Cuba había luchado (Alburquerque, 2017b). En Chile, Salvador Allende asumió la presidencia en 1970 desplegando una política exterior tercermundista que comulgaba plenamente con el ejemplo cubano. En Panamá, Omar Torrijos 
se declaraba un admirador de Fidel Castro y su adhesión al No Alineamiento también se encontraba mediatizada por la influencia cubana. Las coincidencias entre la Nicaragua sandinista y Cuba se reflejaron también en el inmediato acto de incorporación del gobierno de Daniel Ortega al MPNA. Algo similar debió ocurrir en Guyana, Surinam y Granada.

Es claro que los países que se integraron a los No Alineados inspirados por posiciones políticas e ideológicas de izquierda compartían con Cuba un diagnóstico similar del orden mundial. También debemos consignar que estos países entraban a un Movimiento con una fisonomía particular que los cubanos habían ayudado a dibujar. En ese sentido, sumarse al Movimiento en los años setenta, en ese entonces en un proceso de radicalización por obra, entre otros, de Cuba, era distinto a integrarse en los sesenta, cuando su tono era más moderado.

\section{Influencia activa}

Esta corresponde a las acciones concretas que el gobierno de Castro emprendió para influir en la aceptación o el rechazo del Movimiento a la incorporación de los países latinoamericanos. Estas acciones fueron ejercidas sobre el Movimiento como entidad y sobre otros miembros del organismo. Obedecían a los deseos expresos de La Habana por intervenir en la composición del Movimiento y hacerlo funcional a sus intereses. La preocupación era en definitiva por la correlación de fuerzas al interior del organismo, vale decir, por la cantidad de miembros que conformaban los bloques que operaban en él. En la perspectiva cubana existía un grupo afín compuesto por los países con una tendencia política más radical, cercanos a la Unión Soviética y contrarios a Estados Unidos y el bloque Occidental (en otras palabras, antimperialistas). Enfrente se situaba Yugoslavia y sus afines, amén de todos aquellos que recelaban del bloque socialista o que derechamente seguían las orientaciones de Washington. En un documento de principios de los ochenta los cubanos explicitaban esta lógica al proponerse, en un evento próximo, "contrarrestar la intención de Yugoslavia dirigida a afectar en contra de Cuba la correlación de fuerzas en el seno del grupo latinoamericano del Movimiento mediante la incorporación en calidad de miembros de países de la región, en particular los observadores" (Balance de la situación en el MNOAL desde la VI Cumbre hasta la Reunión Ministerial en la India, La Habana, p. 22; Alburquerque, 2019).

En La Habana calculaban con prolijidad cómo afectaba a esta correlación el ingreso de cada nación del continente; la complejidad radicaba en que los países permanecían... pero los gobiernos cambiaban, por lo cual se podía promover la inclusión de un país con un gobierno afín, que al cambiar de gobernantes podía mudarse a la vereda contraria. Hacia 1980 los cubanos constataban que

El Grupo Latinoamericano en el Movimiento sufrió profundas transformaciones. Cuba dejó de ser elúnico Gobierno Revolucionario en el mismo al unírsenos Granada y Nicaragua, pero por otra parte los cambios ocurridos en Perú, Jamaica y Bolivia fortalecieron las tendencias reaccionarias... Podemos esperar que Panamá, Guyana y en menor medida Perú, permanezcan en el centro y nos enfrentaremos a Argentina, Bolivia, Jamaica y en menor medida TrinidadTobago, mientras los observadores de la región favorecerán con sus comentarios la posición de estos últimos (El MNOAL y los preparativos para la Conferencia Ministerial de Nueva Delhi, La Habana, 29 de noviembre de 1980, p.7). 
Se trataba de una dinámica maniquea que reflejaba la intensidad con que se vivía la lucha sectorial en el MPNA, donde nada quedaba al azar y cada jugada era estudiada con detención: Es necesario decidir el trato que otorgaremos a los países latinoamericanos que son solo observadores: Barbados, Bolivia, Brasil, Ecuador, México, Panamá, Uruguay y Venezuela. De hecho ya aceptamos la participación de México, Argentina y Panamá, que han comunicado oficialmente sus delegaciones observadoras. Debe decidirse si invitamos al resto o excluimos a Brasil y sus aliados. La tendencia predominante declarada entre los principales miembros del Buró es invitar a los que mantienen vínculos con Cuba o una política en general amistosa. En la realidad, el sentimiento general es que se invite a todos. Nuestra proposición es invitar, además de los países mencionados, a Venezuela y Barbados (Carta dirigida al canciller Raúl Roa, La Habana, 6 de marzo de 1975).

Se aludía entonces a criterios de inclusión/ exclusión que determinaban la actitud hacia cada país y que remitían a las necesidades coyunturales de la política exterior cubana. En los años sesenta el eje radicaba en la relación con Estados Unidos y la Organización de Estados Americanos. Era en esta institución donde, según La Habana, se revelaba la identidad de cada gobierno. El canciller Raúl Roa lo expresaba así:

Cuba debe propiciar la invitación de los países de América Latina con los cuales mantiene relaciones. En cambio, debe oponerse, aunque con matices, a que sean invitados los países que no tienen relaciones con Cuba y, particularmente, Venezuela. Los países que han roto con Cuba se han alineado junto al Imperialismo, han seguido sus dictados, se han prestado a la política de guerra fría en América (Carta de Raúl Roa a embajador cubano en Ghana,
Armando Entralgo; La Habana, 17 de marzo de 1964, p.3).

La mera pertenencia a la OEA no significaba a priori la exclusión de un país, de hecho los cubanos reconocían "países que resisten la política agresiva norteamericana, no han roto sus relaciones con Cuba y mantienen en la práctica, una política de coexistencia factual, con nuestro país"; tales países, contribuyentes a la paz mundial, perfectamente podían admitirse en los No Alineados (Acerca de la política exterior del gobierno venezolano, La Habana, 15 de junio de 1964, p.12). Venezuela, que por estos años captaba singular antipatía, era calificada como un servil "perro de presa del Imperialismo norteamericano." (Carta de Raúl Roa a embajador cubano en la URSS Carlos Olivares, La Habana, 6 de agosto de 1964, p.2). Рara mayor claridad se comparaba su caso con el de Bolivia, país que "no había tomado la misma parte que Venezuela en la viabilización de un ataque imperialista contra Cuba,... incluso Bolivia había votado en la OEA contra las sanciones y... solo más tarde, quizá por presiones económicas, se había plegado a los deseos del imperialismo" (Comunicado de Oscar Mas, funcionario cubano de la embajada en Moscú, 9 de septiembre de 1964, p.1).

Pero tampoco los bolivianos tendrían un camino expedito. Ya en los setenta, en Cuba objetaron con firmeza un intento boliviano por integrarse al Movimiento, aduciendo que "la presencia de Bolivia cambiaría la correlación de fuerzas en el Grupo latinoamericano y haría muy difícil lograr que se continúen aprobando párrafos de apoyo a las causas antimperialistas en el Continente" (Memorándum de Viceministro José Viera a Ministro de Relaciones Exteriores Isidoro Malmierca, La Habana, 19 de noviembre de 1977). Era entonces el signo político del gobierno boliviano lo que generaba el rechazo. Más aún, el interés de Bolivia representaba 
una "clara maniobra imperialista encaminada a hacer fracasar dicha conferencia (La Habana) y el ejercicio de la dirección del movimiento por parte de nuestro país". Así, su ingreso semejaría “la introducción de un 'caballo de Troya' que el imperialismo tendría intención de hacer penetrar en sus filas [del MPNA], para debilitarlo y dividirlo aún más". La coyuntura -la futura presidencia cubana del Movimiento- incidía con fuerza en las consideraciones de la isla. Se explicaban, además, dicho interés como expresión del deseo boliviano de "mejorar su 'cara interna' y mostrarse más democrática e independiente en su política exterior, intenciones que apoya la administración Carter." (Memorándum de la Dirección de Conferencia Especiales y MPNA a viceministro Pelegrín Torras, La Habana, 29 de noviembre de 1977, p.1). Con la aparición de Estados Unidos se cierra el círculo de factores que condicionaban la política cubana: primero, el signo político del país; segundo, la correlación de fuerzas en el organismo; y tercero, la oposición en todos los frentes a Estados Unidos.

Con tanta seriedad se tomaban el hecho en Cuba que se ideó un plan de acción para frenar las ambiciones bolivianas:

a) Elaborar un despacho de Prela [Prensa Latina, la agencia noticiosa cubana] que cuestione la condición de No Alineado de Bolivia; b) Elaborar otro despacho con declaraciones de patriotas bolivianos contra el régimen de Banzer y su intento de ingresar a los No Alineados; c) Buscar y denunciar toda relación entre Bolivia y los regímenes racistas. (Memorándum de Viceministro José Viera a Ministro de Relaciones Exteriores Isidoro Malmierca, La Habana, 19 de noviembre de 1977).

Se opuso férrea resistencia también a la inclusión de Brasil en el No Alineamiento, con un argumento similar a los esgrimidos contra Venezuela y Bolivia: sumisión a los dictados de Estados Unidos, con el agravante de ser regido por una dictadura militar anticomunista. A inicios de los setenta, una delegación cubana manifestaba

su más categórico repudio a la presencia de los representantes del fascismo brasileño, régimen típicamente gorila, reaccionario y entreguista, que pretende erigirse en polizonte de la injerencia yanqui en América Latina y aspira a desempeñar el grotesco papel de subimperialismo alquilado. (Discurso del Doctor Raúl Roa García, Ministro de Relaciones Exteriores de la República de Cuba en la IV reunión de ministros de relaciones exteriores de Países No Alineados, Guyana, 8-11 agosto, 1972, La Habana, p.5).

El propio Fidel Castro en la Conferencia de Argel de 1973, preocupado por la asistencia de Brasil como observador, proclamó: “¡Esperamos que nunca semejantes gobiernos...sean admitidos en el movimiento de los No Alineados!" (Fidel Castro, Discurso pronunciado en la IV Conferencia Cumbre, celebrada en Argel del 5 al 9 de septiembre de 1973, La Habana, p.6).

Sin embargo, los cubanos sabían que tales maniobras no pasaban desapercibidas y que podían ser acusados de impedir el crecimiento del Movimiento y de minar su unidad. Aún sobre el tema de Brasil, en un diálogo con Vojin Dakovic, embajador de Belgrado en La Habana, estas posiciones se transparentaron. Ante los reparos cubanos al ingreso de Brasilia, "el embajador reaccionó tratando de justificar[lo], caso de que lo intentara, con el argumento de que lo fundamental ега mantener la unidad de los No Alineados". Рara Dakovic "no era fácil rechazar a un país del Tercer Mundo que solicitara su 
ingreso", agregando que "no podía rechazarse a ningún país por razones ideológicas". Cuba especificaba, a continuación, que la adhesión de Brasil al Tratado Interamericano de Asistencia Recíproca (TIAR) lo invalidaba como país no alineado; ante ello, el yugoslavo, aun aceptando ese argumento, instaba a "tener en cuenta los intereses primordiales en la reunión y no frustrarlos por un objetivo secundario." (Memorándum de Viceministro Pelegrín Torras a Ministro Raúl Roa, La Habana, 6 de julio de 1972, pp.1-2).

En la óptica cubana, entonces, el verdadero problema de Brasil no estribaba en ser gobernado por una dictadura de derecha, sino en su comportamiento proclive a Estados Unidos. Así ocurría también en el caso de Argentina, aunque en sentido contrario.

Argentina se había afiliado a los No Alineados en 1973 durante el gobierno de transición pre-peronista de Raúl Lastiri, y en virtud de un señero pensamiento tercermundista enraizado en la Tercera Posición creada por el propio Juan Domingo Perón. Sin embargo, poco duró el compromiso con esas ideas, pues ya durante el segundo gobierno del caudillo se empezaron a imponer tendencias derechistas. El golpe de 1976 consagró en el poder al ala radicalizada del ejército, adscrita además a la Doctrina de Seguridad Nacional, que no incluía entre sus simpatías ni a Cuba ni al No Alineamiento ni al Tercer Mundo. No obstante, los caminos de la Junta y del MPNA terminarían por cruzarse.

Algo similar le ocurriría a Cuba. El gobierno de Fidel observaba con recelo la actuación argentina en Colombo el año 1976 y la indiferencia hacia el Movimiento, todo esto "a pesar de que el Movimiento se ha solidarizado con las reclamaciones de Argentina sobre el territorio de las Islas Malvinas" (Evaluación del desenvolvimiento y resultados de la Conferencia respecto a la América Latina, La Habana, 21 de agosto de 1976, p.2). Sin ir más lejos, los cubanos prepararon el siguiente texto para ser recogido por el resto de los miembros concurrentes a la cumbre:

La Conferencia, en el caso especial y particular de las Islas Malvinas, apoyó firmemente el justo reclamo de la República Argentina y exhortó al Reino Unido a proseguir activamente las negociaciones encomendadas por las Naciones Unidas con el objeto de restituir dicho territorio a la soberanía argentina y poner fin así a esa situación ilegal que aún persiste en el extremo meridional del continente americano. (Propuesta Cubana de Declaración Final, $V$ Conferencia de Jefes de Estados y Gobiernos de los Países No Alineados [Colombo, 16-19 de agosto de 1976], La Habana, p.20).

Sería justamente el problema de las islas lo que cambiaría la relación entre La Habana y Buenos Aires. La guerra de las Malvinas en 1982 fue interpretada en Cuba como una reivindicación legítima que debía unir a América Latina y forzar a Estados Unidos a definirse frente a las obligaciones que le imponían el TIAR y la OEA. En su discurso en Nueva Delhi, Fidel Castro volvió a condenar "la guerra colonial de la señora Thatcher", aclarando que Cuba, "a pesar de las diferencias ideológicas y políticas que la distinguen del Gobierno argentino, no vaciló en apoyar la justa demanda de ese noble pueblo" (Fidel Castro, "Discurso ante la VII Cumbre. Nueva Delhi 7 de marzo de 1983", La Habana, pp. 15-16). De vuelta en su país, Castro se dirigió a su par argentino, Reynaldo Bignone:

En su discurso, tuvo usted expresiones generosas de reconocimiento al trabajo 
desarrollado por Cuba durante el complejo período en que ejerció la Presidencia del Movimiento. Deseo agradecerle profundamente sus palabras, en las que reconozco sus sentimientos de afecto y amistad hacia nuestro pueblo. Le agradezco también sus cálidas y amistosas expresiones hacia mi persona. (Carta de Fidel Castro a Reynaldo Bignone, La Habana, 1 de abril de 1983, p.1).

Cuba establecía los factores prioritarios en la determinación del trato dispensado a los demás países; así, se brindaba amistad y apoyo a Argentina, primero porque ésta combatía el corazón del imperialismo, y segundo, porque reconocía la labor cubana en la testera del Movimiento. Así, pasaba a segundo plano la divergencia ideológica y la indiferencia argentina en pretéritas etapas del No Alineamiento.

Sería la permanencia de Chile en el Movimiento la que provocaría la explicitación definitiva del concepto cubano de No Alineación. Los cubanos habían saludado el ingreso del gobierno de Salvador Allende al MPNA. Por fin encontraban un socio latinoamericano, y en efecto alcanzaron a trabajar en productiva coordinación Las notables coincidencias programáticas entre ambos gobiernos quedaron estampadas en las opiniones cubanas sobre un proyecto confeccionado por Chile referente a empresas transnacionales: "La delegación chilena redactó un excelente preámbulo político denunciando al imperialismo, colonialismo y neocolonialismo como los principales enemigos de los países en vías de desarrollo", felicitándose al mismo tiempo por las proyecciones que auguraba el trabajo en común: "La consulta y coordinación constantes que caracterizaron las relaciones entre nuestras delegaciones fueron realmente el factor clave en los éxitos alcanzados" (Comisión económica, La Habana, c1972, p.3).
El Golpe de Estado de 1973 desbarató esa alianza y provocó honda frustración entre los cubanos, quienes en adelante desplegarían distintas formas de solidaridad con el exilio chileno. Una de ellas se expresó en el MPNA, donde se extremó el esfuerzo por marginar a la junta militar chilena de todas las reuniones de la entidad. Fidel Castro proclamaba en Colombo que no se trataba de "exigir una continuidad ideológica entre las representaciones de un país miembro en el seno del Movimiento de los No Alineados, sino de establecer la esencia misma de ese Movimiento", enunciando una verdadera declaración de principios del No Alineamiento:

La pertenencia al Movimiento...no se cumple con una simple ausencia de compromiso con bloques militares sino que implica, además, la adhesión a un programa de transformaciones que permita a los pueblos salir de la esclavitud colonial o neocolonial y emprender las vías del desarrollo y el bienestar. Los que se imponen a sus pueblos por el crimen y la violencia neofascista, ya sea para mantener viejas estructuras feudales, ya para aplastar o impedir los cambios revolucionarios, no pueden ser considerados, con legitimidad, como integrantes de nuestro movimiento. (Discurso de Fidel Castro en la V Conferencia Cumbre de Colombo, 16-19 de agosto de 1976, La Habana, p.5).

La situación de Chile ha servido para redefinir el No Alineamiento en términos acordes con la situación internacional de Cuba. Ante los cuestionamientos por la asociación de Cuba con la Unión Soviética, y ante su pertenencia a uno de los bloques en disputa, la nueva concepción se fundaba en el grado de implicación de un gobierno con las transformaciones necesarias para disolver la esclavitud colonial (o neocolonial) y alcanzar el desarrollo, excluyendo de esa 
manera a aquellos gobiernos que por vía de la represión frenaban los legítimos ímpetus revolucionarios de sus pueblos. Lo decisivo para el No Alineamiento era la liberación nacional -lograda o pretendida- de las cadenas del imperialismo, y no la independencia frente a los bloques. Entre líneas, por tanto, se hallaba el antimperialismo -base además de la alianza natural entre la URSS y el Tercer Mundo- como el común denominador de los No Alineados.

El Movimiento no poseía la atribución de expulsar a un miembro, pero como los mítines funcionaban por invitación, los cubanos y sus aliados lograron evitar que el gobierno de Pinochet fuera invitado. Así se excluía de facto a un país. Pero no fue todo. El gran objetivo consistió en hacer participar a un grupo de exiliados organizados en la Resistencia Chilena (Antifascista) en reemplazo de la junta militar, idea promovida por Cuba y secundada por Argelia. Aunque los exiliados solo consiguieron intervenir en algunas conferencias como invitados, y no en calidad de miembro pleno como era su intención, la meta de marginar al Chile de Pinochet se cumplió a cabalidad.

La instalación de los exiliados en el MPNA se relacionaba con otra constante de la política que Cuba puso en práctica en el No Alineamiento: la invitación a los movimientos de liberación nacional del continente, comprendiendo grupos guerrilleros y partidos políticos. Se pretendía que concurrieran a las conferencias y tuvieran allí el mayor espacio posible, e idealmente que fueran integrados como miembros oficiales. Ya en la conferencia de El Cairo del año 1964, los cubanos justificaban su empeño:

Sonmovimientoscaracterizados, engeneral, por una clara conciencia antimperialista, dos de ellos-Guayanay Puerto Rico-sonuna viva denuncia del imperialismo y colonialismo norteamericano. Su participación ayudará a radicalizar la Conferencia o en su caso, a desenmascararla. Se caracterizan también por su solidaridad con la Revolución Cubana y nuestra delegación podrá utilizarlos eficazmente, en el curso de la Conferencia. (Sobre la participación de los movimientos de liberación de los territorios coloniales (americanos) en la II Conferencia de Países No Alineados, La Habana, 16 de mayo de 1964, p.1).

Esta era otra variante de la influencia activa ejercida por Cuba, aunque con efecto diferido, ya que se incentivaba y promovía la participación de actores que en un plano ideal llegarían a convertirse en gobernantes de un país y cuyo siguiente paso natural sería adherirse al No Alineamiento.

En realidad, son escasas las ocasiones en que Cuba aplicó una acción favorable a la inclusión de Estados latinoamericanos. En plena década del setenta tenemos una declaración en esa línea: "La sección del documento dedicada a Latinoamérica...debe contener una invitación para que Venezuela, Ecuador y Panamá puedan integrar el grupo de los No Alineados con ocasión de la Conferencia de Lima" ("Reunión Ministerial de la mesa de Países No Alineados. Objetivos de la reunión de La Habana. Comunicado final", La Habana, marzo, 1975). Hacia 1983 descubrimos otro caso, también relacionado con el país que otrora fue apartado, Venezuela. Así se pronunciaba el canciller Malmierca en reunión con un representante de esa nación:

Nosotros necesitamos el fortalecimiento del Movimiento, pero también necesitamos fortalecer la unidad de nuestros países... Por eso estamos dispuestos a tratar de contribuir, si Venezuela lo considera conveniente, aceptable, a que se eliminen 
las reservas que Guyana ha presentado a la admisión de Venezuela. (Conversación con [Manuel] Pérez Guerrero en Documento sin título 2, La Habana, 10 de enero de 1983, p.6).

Podría atribuirse esta postura más positiva a que Cuba, a estas alturas, no se jugaba a fondo por conseguir el liderazgo del Movimiento y atravesaba por cierto retraimiento; de hecho, un documento de la misma época consignaba la opinión cubana ante nuevas posibles incorporaciones, señalando, a propósito de Colombia, que "no objetaríamos su ingreso. $\mathrm{Ha}$ dado pasos en su política exterior que contribuyen a crear las condiciones para su admisión"; y de República Dominicana, que "no nos opondremos a su participación como invitado." Pero la misma fuente recreaba las aprehensiones conocidas, pues, sobre Honduras, anunciaba que "nos opondremos a su ingreso como observador para lo cual debemos coordinar particularmente con Nicaragua y con los amigos NOAL". Y frente a la solicitud de Bahamas para insertarse como miembro pleno, precisaba: "estimamos que la misma está inspirada por Washington y Londres. El MINREX [cancillería cubana] efectúa un estudio para precisar si existen bases militares imperialistas en su territorio." ("Principales cuestiones políticas a examinar por el Buró de Coordinación en Nueva York como Comité Preparatorio de la VII Conferencia Cumbre", La Habana, 18 de enero de 1983).

\section{Conclusiones}

Cuba influyó de modo heterogéneo sobre la participación de naciones latinoamericanas en el No Alineamiento. Su condición de primer integrante continental del Movimiento sin dudas trazó un camino que, aunque con demora, un nutrido grupo de países también siguió. Aunque los cubanos se comprometieron a fondo con el espíritu tercermundista, entendido como solidaridad con el proceso de descolonización en clave antimperialista, se aprecia que ello no decantó en un esfuerzo proselitista por persuadir a otros países del continente a integrarse al Movimiento. Al contrario, desde La Habana se maniobró con objeto de impedir el ingreso de naciones regidas por gobiernos que presumiblemente asumirían posiciones contrarias en la asamblea de la entidad. Venezuela, Brasil, Bolivia, el Chile de Pinochet, vieron frustradas sus expectativas debido a la oposición cubana. En el periodo comprendido las razones de lo anterior no parecen ser las mismas. En los sesenta Cuba no asignaba al Movimiento gran relevancia para el cumplimiento de su objetivo primordial -la supervivencia de la Revolución-, aunque sí lo veía como una instancia adecuada para neutralizar la política hostil de Estados Unidos; en los setenta, en tanto, el MPNA devino uno de los pilares de su política exterior, intensificando su acción con el fin de liderarlo y orientarlo hacia la alianza con el orbe socialista. Si Cuba se propuso controlar la presencia latinoamericana en el Movimiento fue porque procuraba seguir instrumentalizando la organización en función de atacar a Washington y de aproximar al No Alineamiento con la Unión Soviética.

¿Fue Cuba un obstáculo a la participación latinoamericana? La respuesta es positiva si consideramos la influencia activa, pues resultan evidentes sus esfuerzos por marginar a determinados países. Sea como fuere, cada caso analizado nos informa de los criterios que guiaban la política exterior de la Revolución. No eran estos, a primera vista, idealistas; al contrario, parecen estrictamente utilitaristas, aunque se revistieran de enunciados ideológicos. Siempre estuvo detrás el cálculo de la correlación de fuerzas en el seno del Movimiento, y el grado de conveniencia 
de la integración de un país u otro. Por cierto, sería una ingenuidad pretender que Cuba hubiera impulsado un No Alineamiento universal en virtud de sus principios tercermundistas. Al mismo tiempo, no afirmamos que lo ideológico haya sido suprimido; tal como otros especialistas, creemos que Cuba equilibraba conveniencia e idealismo en su política exterior, como por lo demás lo han hecho y seguirán haciendo la mayoría de los Estados del mundo. Por otra parte, desde un ángulo especulativo podríamos preguntarnos: ¿Qué habría cambiado si hubiera predominado el idealismo? Quizá Cuba habría incentivado la mayor presencia posible de países del continente, en coherencia con su vocación tercermundista y latinoamericanista; es posible que hubiera pensado más en los pueblos de los países candidatos que en los gobiernos de turno; habría probablemente impedido a la dictadura argentina participar en el Movimiento tal como hizo con la chilena.

Más claro es el hecho de que para Cuba la relación con los países latinoamericanos se definía en términos internacionales y no en términos bilaterales. Cuba se concebía luchando una partida global y en relación directa con las grandes potencias, que fungían como sus principales referentes. No deja de ser paradójico, en este sentido, que el Movimiento de Países No Alineados fuera, para Cuba, un instrumento que le permitía batallar contra Estados Unidos y colaborar con la Unión Soviética. La Guerra Fría en la política latinoamericana se hacía presente una vez más, eclipsando las dinámicas históricas regionales.

\section{Fuentes primarias}

Acerca de la política exterior del gobierno venezolano, La Habana, 15 de junio de 1964, p.12.
Balance de la situación en el MNOAL desde la VI Cumbre hasta la Reunión Ministerial en la India, La Habana, p. 22.

Carta confidencial del embajador de Cuba en Belgrado al presidente Osvaldo Dorticós, c. 1964.

Carta de Fidel Castro a Reynaldo Bignone, La Habana, 1 de abril de 1983, p.1.

Carta de Raúl Roa a embajador cubano en Ghana, Armando Entralgo; La Habana, 17 de marzo de 1964, p.3.

Carta de Raúl Roa a embajador cubano en la URSS Carlos Olivares, La Habana, 6 de agosto de 1964, p.2.

Carta dirigida al canciller Raúl Roa, La Habana, 6 de marzo de 1975.

Castro, F.: Discurso pronunciado en la IV Conferencia Cumbre, celebrada en Argel del 5 al 9 de septiembre de 1973, La Habana, p.6.

Castro, F.: Discurso ante la VII Cumbre. Nueva Delhi 7 de marzo de 1983, La Habana, pp. 15-16.

Comunicado de Oscar Mas, funcionario cubano de la embajada en Moscú, 9 de septiembre de 1964, p.1.

Comisión económica, La Habana, c. 1972, p.3

Conversación con [Manuel] Pérez Guerrero en Documento sin título 2, La Habana, 10 de enero de 1983, p.6.

Discurso de Fidel Castro en la V Conferencia Cumbre de Colombo, 16-19 de agosto de 1976, La Habana, p.5.

Discurso del Doctor Raúl Roa García, Ministro 
de Relaciones Exteriores de la República de Cuba en la IV reunión de ministros de relaciones exteriores de Países No Alineados, Guyana, 8-11 agosto, 1972, La Habana, p.5.

El MNOAL y los preparativos para la Conferencia Ministerial de Nueva Delhi, La Habana, 29 de noviembre de 1980, p.7.

Evaluación del desenvolvimiento y resultados de la Conferencia respecto a la América Latina, La Habana, 21 de agosto de 1976, p.2.

Memorándum de la Dirección de Conferencia Especiales y MPNA a viceministro Pelegrín Torras, La Habana, 29 de noviembre de 1977, p.1.

Memorándum de Viceministro José Viera a Ministro de Relaciones Exteriores Isidoro Malmierca, La Habana, 19 de noviembre de 1977.

Memorándum de Viceministro José Viera a Ministro de Relaciones Exteriores Isidoro Malmierca, La Habana, 19 de noviembre de 1977.

Memorándum de Viceministro Pelegrín Torras a Ministro Raúl Roa, La Habana, 6 de julio de 1972, pp.1-2.

Propuesta Cubana de Declaración Final, V Conferencia de Jefes de Estados y Gobiernos de los Países No Alineados [Colombo, 16-19 de agosto de 1976], La Habana, p.20.

Sobre la participación de los movimientos de liberación de los territorios coloniales (americanos) en la II Conferencia de Países No Alineados, La Habana, 16 de mayo de 1964, p.1.

Reunión consultiva, La Habana, 1969.

Reunión Ministerial de la mesa de Países No
Alineados. Objetivos de la reunión de La Habana. Comunicado final, La Habana, marzo, 1975.

Principales cuestiones políticas a examinar por el Buró de Coordinación en Nueva York como Comité Preparatorio de la VII Conferencia Cumbre, La Habana, 18 de enero de 1983.

\section{Bibliografía}

Alburquerque, G. (2018): “Cuba y la Unión Soviética en el Movimiento de Países No Alineados", Universum, próxima aparición.

Alburquerque, G. (2017a): “Cuba en el Movimiento de Países No Alineados: el camino al liderazgo. Causas y motivaciones. 1961-1983", Caravelle, 109, pp. 181196.

Alburquerque, G. (2017b): "No alineamiento, tercermundismo y seguridad en Perú: la política exterior del gobierno de Juan Velasco Alvarado (1968-1980)", América Latina Hoy, 75, pp. 149-166.

Alburquerque, G. (2019): "La pequeña guerra fría entre Cuba y Yugoslavia en el Movimiento de Países No Alineados, 1961-1983", en J. P. Silva Escobar y G. Alburquerque Fuschini, eds., Variaciones sobre Latinoamérica. Política, cultura y sociedad, en prensa.

Allison, R. (1988): The Soviet Union and The Strategy of Non-Alignment in the Third World, Cambridge, Cambridge University Press.

Benemelis, J. (1990): “Cuba's African Relation”, en G. Fauriol y E. Loser, eds., Cuba: The International Dimension, New Brunswick, Transaction Publishers.

Dallanegra Pedraza, L. (1984): Participation of LatinAmerica and Caribbean Countries into Nonaligned Movement. Disponible en web: http://luisdallanegra. bravehost.com/Amlat/amlanoal.htm [Consulta: 18 
May 2017].

Domínguez, J. (1989): To Make a World Safe for Revolution: Cuba's Foreign Policy, Cambridge MA, Harvard University Press.

Harmer, T. (2013): El gobierno de Allende y la Guerra Fría interamericana, Santiago, Ediciones Universidad Diego Portales.

Friedman, J. (2015): Shadow Cold War. The sino-soviet competition for the Third World, Chapel Hill, North Carolina, University of North Carolina Press.

Ramírez, S. (2000): Los No Alineados voceros del sur? A propósito de la presidencia colombiana del Movimiento, Bogotá, Tercer Mundo Editores.

Rusell Riechers, C. (2012): Cuba and the Non-Aligned Movement: Interactions of Pragmatic Idealism, Washington, School of International Service, American University.

Recibido: 15 de octubre de 2018

Aceptado: 20 de diciembre de 2018 